\title{
THE EFFECTS OF TECHNOLOGY-ENRICHED SCHOOL INTERVENTION: A MULTIPLE CASE-STUDY ANALYSIS
}

\author{
BetTy Collis and Gerrit Carleer \\ Faculty of Educational Science and Technology, University of Twente, Postbus 217, 7500 AE Enschede, \\ The Netherlands
}

\begin{abstract}
Technology-enriched school projects are initiatives in real school settings that infuse extra computer-related resources and teacher support and training into a school and then, over a period of years, stimulate and study the school's response to the technology. Such projects have occurred in many countries. Typically the projects include a research component, but synthesizing the effects of such longterm interventions in an institution is challenging. In this study, a multiple case-study approach was used to analyse experiences from nine such technology-enriched school projects, involving six countries, 19 schools, and more than 15,000 students, to extract the dominant outcomes of such long-term interventions. In this article, a summary of the main outcomes and experiences extracted from the analysis is given. A parallel focus of the analysis is the question of methodology for research in such environments. How can the effects of technology-enriched school interventions be measured and synthesized? What aspects of the experiences can be generalized to other technology-using schools? The study addresses these issues through the framework of seven research questions relating to technology-enriched schools and responds to the questions based on the nine case studies.
\end{abstract}

\section{INTRODUCTION}

Investigations of the potential effects of computer use in the school setting are frequently concluded with comments about constraining conditions in the school and how these need to be addressed before realistic hopes of any substantial impact of computer use in the school can be met. These constraints relate to inadequate time; insufficient financial resources, equipment and software; inadequate technical support; and also limited institutional support, e.g. [1-3]. Constraints are not limited to quantity but also to quality: better targeted on-going support, information access, ideas for curriculum integration, and interaction in supportive human networks are also acknowledged as important [4,5], and their lack is a serious constraint on the likelihood that computer use will make a substantial impact in the school[6,7]. And even more, new perspectives on educational organization are also seen as necessary preconditions for computer use to be effective in the school setting. Different ideas about curriculum, different approaches to inservice, different ways of forming partnerships with others outside the school-all are being called for as necessary before computer use will realize its potential in the educational system $[8,9]$.

\section{Technology-enriched school projects}

Technology-enriched school (TES) projects are initiatives in real school settings that try to reduce or remove as many of the problems and constraints and in their place stimulate as many of the qualitative changes as possible-to optimize the likelihood of meaningful learning effects connected with computer use in schools to emerge. These sorts of projects are occurring in many different places in the world, described by different names and worked out in different fashions, based on local circumstances, e.g. $[10,11]$. However, certain conditions are usually present: such projects take place in real school settings, with multi-partner involvement, last over a multi-year period of time, and involve the infusion of extraordinary computer-related resources and support into the school relative to local conditions. The partnerships involve not only the school and researchers, but often the private sector and even the local community. The whole school is involved, and the focus of the activity is to stimulate and facilitate change throughout the school, for students, teachers, curriculum, and the organization and functioning of the school as a whole[12].

Research reports are beginning to emerge about such projects, e.g. the bibliography of the Apple Classroom of Tomorrow Project [13], but many of the projects are not represented in conveniently accessible research literature. Often reports are considered descriptions of work in progress and 
therefore written for internal circulation only, or are not in English and thus limited in international circulation. More generally, research analyses may even be seen as inappropriate for evolving, exploratory situations, where critical scrutiny may be interpreted by participants as disruptive and even counter-productive to the development of working relationships between school, private sector, community, and university [14]. Thus the benefits of the experiences tend to be limited to those in the circle of the project; a missed opportunity for practice and theory on a broader scale.

\section{Methodological and theoretical challenges}

More is at issue than the question of improving information dissemination from technologyenriched projects. Finding an appropriate theoretical framework and methodological approach to study what occurs in these complex, evolving environments is also needed [15]. Most of the TES projects begin, not as an experiment grounded in a particular theoretical framework but as a communal response to some opportunity to improve what happens with computers in schools. Research in such environments is often formative evaluation, directed at better tailoring of the project execution to local circumstances [16]. It may be difficult for those working within a TES project to find a balance between local project-execution concerns and theoretical issues of general scientific interest.

In addition, an explicit theoretical framework is often missing in TES projects, probably because of the multi-partner, multi-agenda background of many projects, and the evolutionary cycles through which such complex projects must go before actual execution. However, there are some theoretical frameworks being explicitly employed in certain TES settings which appear to be applicable to such projects in general and which could serve as candidates for a shared theoretical framework. Among these are the so-called ecological and systems approaches. Both are theoretical frameworks for addressing the question of how an innovation affects activity, climate, and output in complex educational settings[17,18].

As an example of the systems approach, the work of Salomon is particularly applicable to TES-project research. Salomon[17] visualizes the effect of a technological innovation in the school as the product of an interdependent system of variables, an output of the system which in turn is embedded in a changed condition of the system. Peled et al. $[18,19]$ extend this systems approach to what they call an "ecological conceptualization" that has as main characteristics that it:

"... does not separate the school and the classroom from community support systems and from local and national policy-making institutions, and perceives the ecology of a classroom as a nested arrangement of systems that affect and are affected by any intervention." $[19$, p. 87]

However, until TES projects more explicitly acknowledge the value of striving for a shared theoretical framework the "action research" orientation occurring in so many of the projects makes them difficult to synthesize and makes the larger synthesis of results from a variety of TES projects particularly challenging [20].

\section{Value of synthesis and the purpose of the study}

The value of such synthesis is clear. By comparing the responses of different school settings as they evolve in their own ways to different combinations and possibilities for the use of computerrelated technologies in schools we can much better search for trends and patterns that transcend the specifics of local situations [21]. Through consolidating such experiences we can better identify critical variables in the school setting that affect the effective use of computers in education, and can better learn which variables are most manipulable in different cultural and situational frameworks $[6,22,23]$. Examination of a number of TES projects can lead to stronger general insights and inferences than can occur through the study of any one project in its locally entangled specifics. Thus, a multiple case-study aproach [24], where each of a number of TES projects forms a case, made cohesive through an ecologically oriented theoretical framework to guide the consideration of experiences from the projects and to support common research questions based on the projects, appears to be valuable. This is the approach and purpose of the current study. 


\section{THEORETICAL FRAMEWORK AND RESEARCH QUESTIONS}

The theoretical framework for our synthesis of experiences from TES projects is one of particular examination of the "supportive ecology" $[19$, p. 87] if the projects in their relation to the treatment-specific processes and outcomes of the projects. In particular, this conceptual orientation formed the framework for the following research questions related to technology-enriched school projects:

(1) What factors stimulate the instigation of a technology-enriched school initiative?

(2) In what ways do the goals of such initiatives affect the process and results of the initiatives?

(3) In what ways does the organization of a TES initiative affect its results?

(4) In what ways does technology affect instruction in technology-enriched schools?

(5) What are successful strategies for the motivation, support, and training of teachers in technology-enriched schools and how do these strategies apply to technology-using teachers in general?

(6) What results are emerging from TES situations?

(7) What factors influence the internal and external validity of TES-project results? What is the contribution of these projects to practice and theory relating to computer use in the regular school setting?

The origin of these questions and their justification are described in the next section, in the context of the procedures for the research analysis.

\section{METHODOLOGY \\ Procedure}

This research began during a workshop for project leaders of technology-enriched school projects, organized as part of the US National Educational Computing Conference, in June 1990 [25]. Invitations for this workshop had been sent to persons in leadership positions in existing TES-type projects, asking them to describe their projects and to participate in a discussion of such projects more generally. Twenty-six persons, from seven countries, accepted the invitation and participated in the 1-day workshop. The organizers of the workshop were the authors of this article. Both of the organizers had also had considerable experience themselves as researchers within TES projects. At the conclusion of the workshop, the participants agreed that such a synthesis of experiences should be done more systematically, should be captured in written form, and should be made available to the broader educational community. From this discussion and its subsequent iterations, agreements were made with project leaders of nine technology-enriched school initiatives for their participation in a reflective meta-analysis of their projects.

On the basis of further discussion and planning, the ecological, system-oriented approach was agreed upon as a common theoretical framework for the synthesis of experiences and a multiple case-study methodology was agreed upon. The multiple case-study approach was to be coupled with the strategy of backward mapping[26] to look for trends and combinations of factors in different TES settings that reappear in association with commonly occurring results in the settings. The project leaders agreed to contribute case-study reports on their projects for the meta-analysis. The case-study reports were to be especially prepared for this analysis, organized around a common outline of questions. The procedures used to generate the questions for the outline were those recommended by Miles [27] and involved iterative dialogue with the project leaders. The questions were grouped under the following headings:

(1) Background, context, and goals of the project

(2) Organization and management of the project

(3) Teacher involvement, training, and support

(4) Current state-of-affairs in the project-what does the project look like in operation?

(5) Results (to date) and recommendations?

Each case study was prepared in interaction with the authors of this article, to facilitate comparison and synthesis of the studies. 
The case studies, when completed, were then synthesized using strategies for the reduction and summary of qualitative data from multiple sites [28], such as clustering, factoring, splitting variables, finding intervening variables, noting patterns and trends, and seeing plausibility. Guidelines from the core methodological reference of Miles and Huberman [28] were used to support the validity of the data coding, analysing and interpreting processes that were used to extract trends, issues and conclusions from the case studies to the research questions of the larger analysis. Full details of the data-reduction process, as well as the full texts of the case studies, are available in book form [29]. This article summarizes the main results of this multiple case-study analysis. For space purposes, the various data-reduction matrices, tables and lists are not given here, but can be found in the book containing the case studies[29].

\section{The cases}

The nine case studies represented nine technology-enriched school projects in six countries, involving a total of 19 schools and approx. 15,000 students. The cases are now briefly described.

Mount Newton Middle School, British Columbia, Canada. This case highlights teacher involvement in the planning of a new technology-enriched building for an existing school and in the parallel planning for teacher inservice and support to exploit the potential of the building [30]. The school enrols 640 students aged 10-14. The intention is to prepare a "technology-enriched environment, that allows for thorough and appropriate uses of computers and related technologies for learning and teaching, as well as administration" $[30, p, 9]$. The key participants in the project are the 36 teachers in the school, including three given special time to become inservice leaders in the school; the administration of the school and of the school district; a school computer aide; the school board of the school district; the provincial Educational Technology Centre; a neighbouring university; and a major hardware and software vendor. The initiative focuses on a 3-yr progression of teacher inservice; on the development and implementation of various applications of the technology at the individual, class, and school level; and on the design and phasing in of the new building itself.

Monterey Model Technology Schools, California, U.S.A. This case involves four schools-two primary (ages 5-11), one middle (ages 11-14), and one secondary (ages 9-12)-with a total of approx. 3200 students [31]. These schools are one of six local sites for a larger, state-wide TES project, called the California Model Technology Schools Project and thus share the overall Project goals of "demonstrating the effective use of technology in instructional delivery and enhancement, as well as in school management" and in "providing policy guidance to government and business decision-makers on the best and most cost-effective strategies for using technology to meet California's educational goals" [31, p. 23]. A key strategy in the 5-yr project is the idea of each teacher developing a Classroom Intervention Plan for learning activities involving technology, as well as a budget and an individualized inservice plan necessary for implementing the learning activities. Project staff, including a training coordinator, a curriculum coordinator, researchers, instructional aides, and specially trained substitute teachers, support and facilitate all these intervention plans, and a site team involving school and district administration also supports the activities. Business partners, universities, parent and other community groups are also involved.

West High School Apple Classroom of Tomorrow, Ohio, U.S.A. West High School is a secondary school (ages 14-18) in which 120 students are participating in Apple Classroom of Tomorrow classrooms [32]. The goal of the initiative is to foster life-long learning through the creation of "a computer-saturated environment that encourages students' initiative, independence, and originality" $[32$, p. 55]. Partners in the project at West High School, in addition to the teachers and other school personnel involved, are the private-sector sponsor, the school district, two universities, and the community at large. Supporting the teachers is a site coordinator, a media specialist, and a music specialist as well as a project supervisor. Involvement of the community in interdisciplinary projects using technology is a key focus of the project.

Technology-enriched schools project, The Netherlands. The Ministry of Education in The Netherlands has been actively stimulating computer use in Dutch schools since 1982. As a way to investigate the potential impact of technology in schools, "the impact that may occur when, after some time, schools will have available a much richer technology-related environment than they have at the moment"' 33, p. 67], the Ministry instigated a project involving three secondary schools, 
the Ministry of Education, and researchers from two universities to work collaboratively in the outfitting of the schools with an exceptional amount of hardware and software as well as close partnerships with research teams for the development of lesson materials, teacher training, and adapted courseware. The project involves the examination of the effects of a TES environment on the organization and administration of the school; on the curriculum ("changes in content, integration of subject areas, changes in time spent on specific subject areas" $[33, \mathrm{p} .67]$ ); the roles and attitudes of the teachers; and the overall teaching-learning process. Special provision was made for each school to have on-site technical support (two persons, one for technical issues and one to manage the use of the various computer laboratories), as well as a teacher trained to be a school computer coordinator. There is a total of 3700 students, aged 12-18, at the three schools.

School No. 56, Romania. School No. 56, in Bucharest, enrols 2500 students, aged 6-14. This TES project is under the management of the Research Institute for Computers in Bucharest, an institute employing more than 1000 employees in research related to computers, electronic equipment, and informatics. Within this institute is a team that has been working since 1984 on various initiatives for computer use within schools and on educational software development. The goal of the current TES project at School No. 56 is to "change the general atmosphere in schools, making the atmosphere more permissive, fully stimulative for pupils' creative capacities, by means of information technologies" [34, p. 80]. Partners in the project, in addition to the school and the Research Institute for Computers, are the Ministry of Education and the National Institute for Educational Sciences. A technician was hired to support the project. Teacher training is emphasized, as well as the development of a collection of computer-assisted lesson activities.

Project Comptown, Israel. Project Comptown is a 5-yr "educational intervention that extensively computerized schools and their "closed environments" in Emory, a small town in Israel" [19, p. 87]. The project involves all six elementary schools (ages 6-14) in the town, with a total of about 2000 students. All 200 teachers in these schools are involved in the TES project. Project partners are the Ministry of Education and Culture; a municipal steering committee including representatives of the local government, teachers, principals, and public representatives; a core group of 68 principals and teachers who actively participated in the planning for the project; and university researchers working on the Management Team, the Training Team, the Development Team, or the Evaluation Team for the project. Major goals of the project included changing "the nature of the traditional 'Book \& Print'-dominated classroom" $[19$, p. 88]; creating a "computer culture" in the schools; and "creating a supportive ecology in which a 'future computer culture' can expand"; so that in turn, the "gap between the school culture and the real-world culture can be narrowed" $[19$, p. 87$]$. Part of the project strategy was to train retired persons and high school students to give technical assistance within the schools.

"School of the Future", F. M. Black Middle School, Texas, U.S.A. The F. M. Black Middle School (ages 11-14) enrols approx. 1200 students. The school's TES initiative has involved various groups from the private sector, as well as the school district and the school. A focus of the project is to provide teacher training and implementation support to "facilitate effective, orderly integration of computers into the school's curriculum and administrative functions" $[35, p .106]$. The original goal of integrating computers into every branch of the curriculum and restructuring the delivery of instruction has evolved into a focus on "working the technology into the school's current instructional organization causing change to become an evolution rather than a revolution" [35, p. 106].

Quinte Lighthouse Project, Ontario, Canada. Quinte Secondary School enrols 900 students, aged 14-18. The school was chosen to be one of six schools to "demonstrate the effective implementation" of computers in Ontario schools[35, p. 115]. After spending considerable effort on establishing hardware and software provisions for schools, the Ministry of Education in Ontario wished to equip various schools with a "computer-rich hardware availability several years ahead of normal. Thus they would be in a position to determine the real potential of the computer for education without the distractions of "not enough equipment', 'not enough support', and so on" [36, p. 115]. All curriculum areas within Quinte School were involved, and the school was supported by a consultant from the local school district; a full-time on-site school specialist to provide ongoing teacher inservice; and a technical assistant. Both the local school district and the provincial Ministry of Education were also involved in the project. 
Netherhall School, Cambridge, U.K. The Netherhall School is comprehensive school of 1400 students, aged 11-18. Unlike the other schools involved in the case studies, Netherhall is a case of a school that itself has taken the initiative of creating and carrying out various technologyenriched initiatives since the 1970s[37]. Thus Netherhall is a case of a school evolving over time through a variety of TES-like projects and in the process becoming very much a technologyenriched school involved in multi-partner initiatives. The philosophy of the school's use of technology is that "stepping stones" are necessary for teachers "to gain confidence to be classroom facilitators of IT, and if all goes well, competent teachers of IT within their subject and across subjects" [37, p. 132]. Thus the school is involved in various projects and initiatives, coordinated within a school-wide plan for IT use, "so that the whole staff can see what the students' experiences are in each year and in other subjects, and are able to ensure that there is no overlap in what is being taught" [37, p. 129]. The development of interactive video learning materials has been one of many recent school projects.

\section{RESULTS OF THE SYNTHESIS OF THE CASE STUDIES}

The results of the synthesis of the case studies will be discussed relative to each of the research questions of the multiple case-study. For each question, a full description of the data analysis can be found in [29, pp. 133-168]. The dominant modes of analysis used were those described by Yin [21] as "explanation building" [21, pp. 107-109], "analyzing embedded units"[pp. 115-116], and "secondary analysis across cases" [pp. 117-119].

\section{(1) What factors stimulate the instigation of a technology-enriched school initiative?}

In six of the cases, the TES project was initiated outside the school, while in the remaining cases, the schools were centrally involved in the instigation of the TES initiative. Five of the cases evolved out of prior regional- or school-level computer-related initiatives, while the other four began more specifically as a special project. Thus the initiative for a technology-enriched project can come from a variety of levels and sources. Most of the schools involved, however, had at least some personnel with prior, extensive experience with computer use. Often a criterion for school involvement was the school leadership-a combination of a forward-looking principal and a teacher in the school with exceptional computer-related knowledge and enthusiasm. All but one of the North American projects had an active industrial partner and the Netherhall School in the UK has had regular collaboration with business or industrial partners. However, the other European cases and the Ontario case were instigated and funded by their ministries of education. The European projects were more likely to have been stimulated by a team of researchers than were the North American projects, where researchers were involved but not as the initiators or agenda-setters of the projects. In summary, there is no particular pattern in the instigation of the TES projects across the cases.

\section{(2) In what way do the goals of the TES projects affect the results?}

It was difficult to synthesize and compare the goals of the technology-enriched school projects described in the case studies. One reason for the difficulty is the likely presence of implicit or broad goals underlying the projects. All of the case study authors might well have agreed, for example, that the eventual improvement of students' abilities to solve complex problems is a basic goal of their whole educational systems, and thus an obvious part of the context of the TES projects. The projects differed in how many of these sorts of general educational goals they explicitly indicated, but it cannot be implied that if a general educational goal is not mentioned it was not important to the project. However, we limited our analysis to what the case-study authors actually stated as explicit project goals. We were able to group the stated goals as student-focused, teacher-focused, school-restructuring focused, and project-execution focused.

Student-focused goals. Relatively few of the stated goals of the TES projects directly relate to students. None of them explicitly set as a target that students will perform better on traditional measures of school achievement. Only one project gave measurable objectives related to student performance, and these were in terms of the computer-use competencies. When students were mentioned as the focus of a project goal, it was generally in terms of process behaviours relative 
to high-level cognitive functioning and stated in terms not conducive to measurement ("Students will become gatherers, analyzers, and managers of information..." [29, p. 136]) or in terms of what the project would do for the student, rather than in terms of what the students might be expected to achieve.

Teacher-focused goals. Many of the projects included goals related to teachers using technology and integrating it into their instructional practice. These sorts of goals were often stated quite broadly. "Utilize the computer's potential for innovative teaching..." or "Use the technology as a tool to enhance the curriculum in the areas of mathematics, science, language arts, social studies, and keyboarding".

School-restructuring goals. Given the many different predictions of the potential of technology to stimulate restructured schools, e.g. $[38,39]$ and the broad and ambitious scope of most of these TES projects, it was interesting that virtually none of the stated goals seem to suggest a restructured school. A number did indicate goals related to enriched, expanded, modernized, and revitalized schools-but more explicit restructuring was not stated.

Project-execution focused. Many of the goals of the projects related to the execution of the projects themselves. Projects were to "demonstrate effective practice", "design a site- or teacherbased planning and decision making model," "create a computer-saturated environment that encourages students' initiative, independence, and originality," "create a computer culture," or other such project-execution focuses[29, pp. 156-158].

Observations related to the project goals. If we intend to use the project goals as standards against which project success can be measured, we can anticipate difficulties. Sometimes this is because a project goal is stated in a complex and unmeasurable way, as for example:

"Make it possible for students to utilize skills and knowledge acquired from the education combined with the tools now provided by technology to make independent, self-directed, self-regulated decisions that will optimize their ability to solve complex problems both in and outside the classroom". [29, p. 137]

But perhaps the most problematic aspect of the project goals relating to eventual measurement of success of the projects is that most goals are stated in terms of what the adults in the project will do during the project, not what students will do or learn. The verbs associated with the stated project goals illustrate this:

"... Prepare a, demonstrate the, provide guidance, disseminate the, make it possible for, design a, create an, use, become, investigate the, change the, familiarize student with, integrate, utilize, develop...."[29, pp. 156-158]

Only one of these verbs is at the start of a goal statement that specifically relates to student activity. All of the rest of verbs lead into goal statements that are stated in terms of what the adults in the project will do. A major assumption in the projects is that the activities in the projects that the adults are doing, all the demonstrating, preparing, investigating, creating, etc. will result in better student outcomes.

\section{(3) In what ways does the organization of a TES initiative affect its results?}

There are clear consistencies in the projects relative to some aspects of organization. All of the cases involved extra personnel in the schools and extra time for some of the existing personnel already in the schools, for a summary see [29, pp. 153-155]. All the projects funded extra personnel for project coordination. Considerable time was invested by all participants in project meetings and internal communication. Most of the projects have complex project infrastructures and management and advisory lines. It was clear in all the projects that teachers need considerable support; this was typically provided for through additional personnel funded by the TES project. Regardless of how the projects were organized, the participants agreed that the support persons working on the projects were essential, and were kept very busy. It appeared that even in technologically enriched environments, computers were still technically too complex for unproblematic use by the average teacher, the way support was provided and organized by the project was seen as a critical aspect of its results. Beyond this, however, there is no other particular trend in the case studies to indicate that one sort of project organization is preferable to others. 


\section{(4) In what ways does technology affect instruction in technology-enriched schools?}

In all cases, computer-related technology was being integrated into instruction in the traditional subject areas. Application software was being used in every project, in particular word processing in support of writing. Desktop publishing was frequently mentioned as a tool. Different types of databases were used in most of the projects, often with a hypertext-type structure. Curriculumspecific software was mentioned in most of the cases, but given less emphasis than applications and tools. Programming languages were only mentioned as being used in two of the cases.

As most of the cases have the majority of their computers in school laboratories, instructional activities utilizing the technology often had to take place outside of the base classroom. Most of the schools have other computers available, in the library, for school administration, and in specialized smaller groupings, and most have multi media equipment. Only one of the 19 schools described in the cases is indicated as specifically rejecting the computer-room concept in order to maximize the dispersion of computers into classrooms.

Many innovative uses of technology were described (although, interestingly, very little mention of microcomputer-based laboratory systems, or of telecommunications). However, in seven of the nine cases little mention was made of interdisciplinary instruction, and the traditional pattern of subject-area organization and assessment did not seem to be changed in most of the settings. In general though, much was being tried and many students were indeed making use of technology in instructional settings, and for their individual work in the schools.

(5) What are successful strategies for the motivation, support, and training of teachers in technologyenriched schools and how do these strategies apply to technology-using teachers in general?

A major common theme in all of the cases was the importance of the teacher in the TES projects. "The key to having a successful plan is to have teachers committed to the program and excited about the prospect of using new technology in their classrooms" [29, p. 139] is typical of statements in most of the case studies. How to stimulate and nurture this commitment and excitement became a major preoccupation of the projects. Many different types of inservice activities were offered, with many different structures, although most often in the school itself and often after school hours. Sometimes the researchers or other project partners from outside the school delivered the inservice, but often the teachers themselves supplied the inservice leadership.

A trend emerged in most of the case studies-inservice tended to begin with some relatively traditional sessions, but quickly evolved toward a more individualized approach. This individualization took different forms in the different projects-mentoring, one-to-one coaching, etc.but generally was on-site and personalized. Such support was valued very highly by project participants. It was also very expensive to provide. Not only must an appropriate person be available on-site, but released time and substitute support for the teachers while they are receiving personalized attention must also be provided. Only one project explicitly talked about moving beyond this labour-intensive support towards more independent teachers. A critical question, but not directly addressed by the projects, is how this very expensive personalized component can be replicated or compensated for in non-project schools.

\section{(6) What results are emerging from TES situations?}

Despite discussions with the case-study authors and explicit requests to indicate "results" emerging from the TES projects, it was very difficult to synthesize outcomes. One of the reasons for this is the overlap between process and product-in a sense, everything that happens in a TES project is a result of the project. Another difficulty is that "results" often relate to a process of change, in attitude, experience, work habits, and approaches to problem solving, that are matters of gradual increase, and thus not much amenable to measurement. More difficulties came from projects in execution being preoccupied with their own activities and seen as still in a state of getting going or experimenting, not states for which it seemed appropriate to talk about "results". However, the researchers did provide a summary of what seemed to each to be the major results of the projects to date. We grouped these into results with regard to teacher change, to student change, to school-level change, and to project self-insight and transfer (see [29, pp. 163-168] for a summary). 
Results with respect to teacher change. All of the case studies indicated that at least some of their teachers were making significant progress, showing willingness to innovate, reflect, and change some of their instructional strategies. Teachers were seen as generally positive about the projects and becoming increasing familiar with computers as tools. Teachers were using computers in an increasing number of ways and in an increasing variety of subject areas.

However, not all the teachers in the TES schools were enthusiastic computer users. And even for teachers who were enthusiastic, on-going support and motivation were acknowledged as important for the teachers' sustained involvement and growth. The case studies also indicated that teachers must be personally committed, need time, and benefit from access to computers outside of the laboratory or classroom.

Results with respect to student change. All of the case studies indicated that their students took naturally to computer use, were generally enthusiastic about computer use, and were moving toward more independent use of computers as tools. Each case study described some kinds of gains in student achievement and/or attitude. The following were among those explicitly stated:

- Increased attention span

- Positive attitudes about technology

- Increased performance on standardized tests and measures of writing proficiency

- Reduction in writing errors

- Increased enthusiasm for writing

- Increased cooperative learning

- Increased spelling skills

- Increased problem-solving ability

- Show more initiative

- Have a deeper motivation for learning

- Make spontaneous contacts for discussions

- Significant gains in handling multiple-inference problems, formulation and testing of hypotheses, data organization skills, and identification of meaningful variables

- Make effective use of technology as a tool[29, pp. 141, 163-168].

However, all of the case studies also indicate important results that could not be directly measured or even described. While all expressed with confidence that excellent results were occurring in the projects, the measurement of much of what was seen as important in terms of what was going on in the projects was not done or not seen as possible to do.

Results with respect to school-level changes. Most of the case studies indicated positive changes in school climate or described important changes in what might be called the school ecology. In more than half of the cases, this kind of school-climate change was described as a dominant and major result of the project.

Results with respect to project-level insights and transfer. All of the case studies indicated that growth in insight and professional awareness among the participants was an important characteristic of the projects. Most of these insights could be expressed as recommendations for other TES-type projects. Major recommendations were:

- Recognize the importance of teacher involvement. For example, "Put people first, especially the teachers..." and "Don't feel guilty for investing resources for staff development at the apparent expense of the students. An investment in a teacher will pay off for hundreds of students in the years to come," and "Stimulate thorough staff involvement in planning and design."

- Give teachers released time and appropriate space for exploration of ideas.

- Provide teachers individualized support and attention and models of instructional practice.

- Focus on curriculum integration ideas.

- Be realistic about the constraints of a TES project, especially during its initial planning and goal setting. Choices will have to be made. "Aim for change to be an evolution, rather than a revolution." [29, pp. 142-143, 163-168]. 
(7) What factors influence the internal and external validity of TES-project results? What is their contribution to practice and theory relating to computer use in schools?

There are, of course, critical concerns relating to both the internal and external validity of the results synthesized from the nine case studies of technology-enriched schools in this analysis. Validity and reliability are always issues in naturalistic, field-based studies, especially where the author is centrally involved in the object under study, e.g. [40,41]. However, the process and product criteria recommended by Lincoln and Guba [42] as indices of the quality of case-study reports we feel have been reasonably met through our procedures. Our own conclusions are also products of decision making and judgement; we can only offer our original source materials and various rounds of data reduction summaries to support the validity of our interpretations.

Taking the results of the synthesis of the case studies as reasonably valid and reliable, a major question then becomes the external generalizability of the findings. Here we can respond in three ways. One way is to say that generalizability is limited, given the very special situations created in the TES projects. We do not, however, take this view. We feel instead that given the rapid growth of technology in ordinary schools, many of the conditions of the TES-project schools are quickly becoming standard in schools in many countries; thus the settings of the technology-enriched school projects of the late 1980s and early 1990s will become more and more typical without the need for special intervention projects in the next decade. Therefore, the generalizability of insights from yesterday's technology-enriched project schools should be reasonably good to tomorrow's technology-enriched ordinary schools. Finally, we believe there is an important message to be learned from these exceptional settings-if, given the best conditions which the teams could implement, change still was difficult to effect, teachers still had problems and need for motivation, and the measurement of success was still hard to document, then we must expect these same problems to occur in regular school settings. We should not be unrealistic in our expectations of computer-related use in schools, but neither should we forget the constant enthusiasm and stimulation that such use seems to bring.

\section{CONCLUSIONS}

In this analysis we have summarized case studies of nine technology-enriched school projects, involving 19 schools in six countries and more than 15,000 students. We have addressed a set of seven core research questions about the projects, based on case studies written by the project leaders. We have focused as well on our own methodology-how can valid, reliable, and helpful conclusions be drawn from complex, long-term, multi-faceted, multi-partner experiences? As we reflect on the cases and on our own analysis, we found ourselves returning regularly to a major question-what does success mean in terms of a technology-enriched school project? We would like to conclude with a few considerations related to this.

Were these projects successful? One way to define success of an educational initiative is to compare results with expectations. However, as we indicated earlier, this is difficult with TES projects, in that the stated goals of the enterprises were often stated very broadly, or in too complex or future-oriented a way to measure, certainly during the tme of the project. Also, many of the project goals were related to project maintenance-but is the actual doing of the project, for example, in terms of numbers of computers and teachers using computers and hours of inservice and contact opportunities for students, enough to indicate success? What about cost-benefit perspectives? Given the amount of money invested in TES projects, can we say the results obtained justify the time and effort spent? Or must we wait again for the long-term payoff? But what about success as a function of enthusiasm? Certainly in this respect the projects are all successesstudents, teachers, most project participants seem to like what they are doing, to be stimulated by it, to find it attractive and interesting. Also, the projects have stimulated much professional activity among the participants, new interactions, new partnerships, new ideas, new activities, and even deeper reflection about the nature of teaching and learning and the school. We believe that with these sorts of results, as well as the more technology-use specific insights and recommendations, the successfulness of the technology-enriched projects reported in these case studies is well supported. 


\section{REFERENCES}

1. Gillman T. V., Change in Public Education: a Technological Perspective. ERIC Clearing House on Educational Management, Eugene, Ore. (1989)

2. Littlejohn T, D., Ross R. P. and Gump P. V., Using microcomputers in elementary schools: implementation issues. Pnper presented at the Annual Meeting of the American Educational Research Association, New Orleans (April 1984).

3. Teles L. and Mitchell, W., Implementing computers in the classroom: issues and concerns in Ontario. CALM Dev. Newsl. 4, 3-4 (1988),

4. Dwyer D. C., Ringstaff C. and Sandholtz, J. H., Teacher beliefs and practices. Part II: Support for changes. ACOT Report \#9. Apple Computer, Inc., Cupertino, Calif. (1990).

5. Sandholtz J. H., Ringstaff C. and Dwyer D. C., The relationship between technological innovation and collegial interaction. ACOT Report \#13. Apple Computer, Inc., Cupertino, Calif. (1992).

6. Collis B., Manipulating critical variables: a framework for improving the impact of computers in the school environment. Paper delivered at EURIT '88, Lausanne (July 1988).

7. Rhodes V., Barriers to innovation: a seminar report. Occasional Paper InTER/11/89. Department of Psychology, University of Lancaster (1989).

8. Bailey G. and Lumley D., Districtwide technology integration. Electronic Learning, pp. 16-17 (May/June 1991).

9. David J. L., Partnerships for change. ACOT Report \#12. Apple Computer, Inc., Cupertino, Calif. (1992).

10. Apple Classrooms of Tomorrow: What's Happening in ACOT? Apple Computing, Inc., Cupertino, Calif. (1992).

11. Sinclair K. E., Microcomputers in Australian education: the IBM Secondary Schools Education Project. Paper delivered at the Annual Meeting of the American Eduational Research Association, New Orleans (April 1988).

12. David J. L., Sterns M. S., Hanson S. and Schneider S., Implementing the Teacher-centered Model of Technology Use: The First 15 Months. SRI International, Menlo Park, Calif. (1989).

13. Bibliography, Apple Classrooms of Tomorrow. Apple Computer, Inc., Cupertino, Calif. (1992).

14. Collis B., Assessment of educational programs: how can we assess "Dynamics and Vision"? Paper presented at the International Customer Executive Seminar, IBM International Education Centre, La Hulpe, Belgium (March 1989).

15. Baker E. L., Sensitive technology assessment of ACOT. Paper presented at the Annual Meeting of the American Educational Research Association, New Orleans (April 1988).

16. Nevo D., The conceptualization of educational evaluation: an analytical review of the literature. Rev. Educl Rese. 53, $117-128(1983)$.

17. Salomon G., Studying the flute and the orchestra: controlled vs. classroom research on computers. Int. J. Educl Res. 14, 526-531 (1989).

18. Peled Z., Peled E. and Alexander G., Ecology and experimentation in the evaluation of information technology interventions in natural classroom settings. Stud. Educl Eval. 17, 419-448 (1991).

19. Peled E., Peled Z. and Alexander G., Computerization of an Israeli school system: Project Comptown. In Technology Enriched Schools: Nine Case Studies with Reflections (Edited by Collis B. and Carleer G.), pp. 87-104. International Society for Technology in Education, Eugene, Ore. (1992).

20. Miranda E. O., Broadening the focus of research in education. J. Res. Dev. Educ. 22, 23-38 (1988).

21. Collis B. A. and De Diana I., The portability of computer-related educational resources: an overview of issues and dircctions. J. Res. Computing Educ. 23, 147-159 (1990).

22. Kell D., Harvey G. and Drexler N. G., Evaluating technology in schools: implications of a research study. Paper presented at the Annual Meeting of the American Educational Research Association, San Francisco (April 1990).

23. McManus J. and Cannings T., The IBM Model Schools Project: a three-year retrospective. Paper presented at the Annual Mecting of the American Educational Research Association, New Orleans (April 1988).

24. Yin R. K., Case Study Research: Design and Methods. Sage Publications, Beverly Hills, Calif. (1984).

25. Ellis E. (Ed.), Proceedings of the National Educational Computing Conference, NECC '90. International Society for Technology in Education, Eugene, Ore. (1990).

26. Fullan M., Miles M. E. and Anderson S. E., Strategies for Implementing Microcomputers in Schools: The Ontario Case. Ministry of Education, Toronto (1988).

27. Miles M. B., New methods for qualitative data collection and analysis: vignettes and prestructured cases. Qual. Stud. Educ. 3, 37-51 (1990).

28. Miles M. B. and Huberman A. M., Qualitative Data Analysis: A Sourcebook of New Methods. Sage Publications, Beverly Hills, Calif. (1984).

29. Collis B. and Carleer G., (Eds), Technology Enriched Schools: Nine Case Studies with Reflections. International Society for Technology in Education, 1787 Agate Street, Eugene, OR 97403-1923 (1992).

30. Elder K., Mount Newton: a technology-enriched middle school. In Technology Enriched Schools: Nine Case Studies with Reflections (Edited by Collis B, and Carleer G.), pp. 9-22. International Society for Technology in Education, Eugene, Ore. (1992).

31. Matray K., California Model Technology Schools: the Monterey perspective. In Technology Enriched Schools: Nine Case Studies with Reflections (Edited by Collis B. and Carleer G.), pp, 23-54. International Society for Technology, Eugene, Ore. (1992).

32. Howard R. and Pratt J., Apple Classroom of Tomorrow: West High School. In Technology Enriched Schools: Nine Case Studies with Reflections (Edited by Collis B. and Carleer G.), pp. 55-66. International Society for Technology in Education, Eugene, Ore. (1992).

33. Moonen J. and Beishuizen J., Technology-enriched schools in The Netherlands. In Technology Enriched Schools: Nine Case Studies with Reflections (Edited by Collis B. and Carleer G.), pp. 67-76. International Society for Technology in Education, Eugene, Ore. (1992).

34. Diamandi I., An information technology school project in Romania. In Technology Enriched Schools: Nine Case Studies with Reflections (Edited by Collis B. and Carleer G.), pp. 77-86. International Society for Technology in Education, Eugene, Ore. (1992).

35. Smith R. A. and Sassi A., School of the Future Project at F. M. Black Middle School. In Technology Enriched Schools: Nine Case Studies with Reflections (Edited by Collis B. and Carleer G.), pp. 105-114. International Society for Technology in Education, Eugene, Ore. (1992). 
36. Holt R., The Ouinte lighthouse Project. In Technology Enriched Schools: Nine Case Studies with Reflections (Edited by Collis B. and Carleer G.), pp. 115-122. International Society for Technology in Education, Eugene, Ore. (1992).

37. Wells A. J., Netherhall School: building for the future on the experience of the past. In Technology Enriched Schools: Nine Case Studies with Refiections (Edited by Collis B. and Carleer G.), pp. 123-134. International Society for Technology in Education, Eugene, Ore. (1992).

38. Collins A., The role of computer technology in restucturing schools. Phi Delta Kappan, pp. 28-36 (September 1991).

39. David J. L., Restructuring and technology: partners in change. Phi Delta Kappan, pp. 37-40, 78-82. (September 1991).

40. Sadler D. R., Intuitive data processing as a potential source of bias in naturalistic evaluations. Educl Eval. Policy Analysis 3, 25-31 (1981).

41. Achilles C. M., The Gruesome Dozen: problems plaguing program/project evaluators. Educl Eval. Policy Analysis 4, $439-442$ (1982).

42. Lincoln Y. S. and Guba E. G., Judging the quality of case study reports. Qual. Stud. Educ. 3, 53-59 (1990). 